\title{
Impostación de la voz
}

\author{
Ana Sofía Vargas Hernández ${ }^{1}$
}

\section{Introducción}

Todas las personas que viven en sociedad deben utilizar, en mayor o menor grado, su voz para poder comunicarse con sus semejantes; pero hay muchos que, por su profesión, necesitan compartir sus ideas más a menudo, y de manera eficiente, con los demás; entre ellos se encuentran los periodistas, los locutores, los actores, los relacionistas públicos y, en especial, los maestros. Pero, no se debe hablar por hablar, hay que hacerlo apropiadamente y con corrección.

En este trabajo se van a tratar algunos aspectos relacionados con la comunicación, con la producción y el uso de la voz, para llegar a la impostación, sin cuyo manejo se estaría usando el instrumento comunicativo de una manera pobre e inútil. Aunque estos aspectos no se pueden tratar aisladamente, por razones didácticas se tocará cada uno por separado.

\footnotetext{
'Profesora de Preecular bilingue en Montessori Nursery and Preschool, Santa Ana, Cos. ta Rica.
} 
El propósito de este escrito es despertar conciencia en los maestros sobre la importancia del buen manejo, y del cuidado que se debe tener del instrumento más usado por ellos en su quehacer diario: la voz, con el fin de que su mensaje llegue de una forma fácil, efectiva y, sobre todo, agradable a sus alumnos. Asimismo, se pretende que los docentes tengan un instrumento que los oriente para cuidar y mejorar su voz.

El trabajo consta de seis apartados principales, éstos son: aspectos generales acerca de la comunicación y teoría sobre la producción de la voz, aspectos por tomar en cuenta para tener una buena voz, la impostación de la voz, enfermedades más comunes de la voz, prevención de los problemas de la voz y, por último, consejos y recomendaciones para cuidar la voz. Como se ve, para desarrollar este trabajo se hizo necesario, primero, tocar algunos aspectos acerca de la producción de la voz y, posteriormente, brindar algunos consejos sencillos y prácticos para el mejoramiento y el cuidado de la voz, con el fin de lograr el objetivo propuesto. El anexo contiene dos ejercicios correctivos por aspecto tratado en el desarrollo de este trabajo.

\section{Generalidades acerca de la comunicación humana}

Para poder entender lo que es la impostación de la voz, es necesario explicar, aunque sea de forma breve, en qué consiste la comunicación y cómo se produce la voz, además de algunos otros aspectos relacionados con el tema en cuestión.

\section{Comunicación}

Etimológicamente, el vocablo comunicación hace referencia a una idea muy simple y clara: común-acción, 
por lo que se puede entender la comunicación como la coordinación de acciones. De una manera más simple, se puede decir que comunicación es el proceso mediante el cual dos o más personas se relacionan para transmitirse 'algo' y lograr el objetivo de llegar a un significado común.

Según Coronado (1994), para que el proceso de comunicación se lleve a cabo deben intervenir los siguientes elementos:

- Un sujeto emisor que se encarga de mandar el mensaje.

- Un sujeto receptor (puede ser plural), a quien va dirigido el mensaje. Este sujeto, en determinado momento, cambia su rol y pasa a ser sujeto-emisor, lo que facilita la comunión de significados.

- Un mensaje, que es el contenido de la comunicación, la información entregada o recibida por los sujetos. El mensaje debe transmitirse mediante un código (representación simbólica), el cual debe ser compartido por los participantes en la situación comunicativa. El código puede ser verbal (oral o escrito) o no verbal (gestos, movimientos, colores, vestuario, tics, poses, imágenes, música, normas, costumbres, entre otros).

- Un canal, que es la parte corporal de los sujetos que se utiliza para enviar y recibir el mensaje, corresponde a los sentidos, por tanto, se puede hablar, por ejemplo, de los canales visual, olfativo, auditivo, gustativo y táctil, así como de los canales oral, gestual y kinestésico (movimiento).

Existe mucha teoría sobre la comunicación (en cuenta las barreras y la manera de eliminarlas); sin embargo, no es posible tratarla toda, pues el trabajo, además de que se extendería demasiado, se dirigiría en otro sentido y se perdería el objetivo original. 
En la comunicación oral se usa, específicamente, la voz, razón por la cual se explicará, a continuación, este aspecto.

\section{La voz}

Posada y Zuliani (s. f.) expresan que la voz es el sonido que se produce cuando una persona expele el aire de los pulmones, el que al salir de la laringe hace vibrar las cuerdas vocales, con tono, con timbre y con intensidad específicos, aspectos característicos de la voz humana.

El tono es el aspecto que define una voz como grave o como aguda, es la mayor o menor elevación del sonido, producida por el mayor o menor número de vibraciones; es la inflexión de la voz y modo particular de expresar algo, de acuerdo con el estado de ánimo o la intención de una persona. Por ejemplo, cuando alguien está alegre dice las cosas casi con un grito, y si está asustado, con una voz entrecortada, pausada o temblorosa.

El timbre es la característica individual, modo propio o característico de producir la voz, es decir, lo que hace que se pueda diferenciar una voz de otra. Así, se pueden encontrar voces graves, agudas, chillonas o nasales.

La intensidad es el volumen de la producción oral. Es la propiedad que tiene que ver con la mayor o menor amplitud de las ondas sonoras. Por ejemplo, si una persona levanta la voz en una fiesta o si la baja al hablar dentro de un templo.

Según Posada y Zuliani (s. f.), estos tres aspectos juntos permiten reconocer a las personas cuando hablan, hacen a las personas únicas e inconfundibles. No hay que creer que si se tiene problemas en alguno de esos aspectos, se tiene que permanecer así, pues es posible, con práctica y ejer- 
cicios, modificar o eliminar el vicio o defecto que se tenga y mejorar la calidad de la voz.

La adecuada utilización de la voz favorece la comunicación entre las personas, por eso es importante cuidarla en todos los sentidos (Vega, 2004).

El ser humano produce sonidos gracias a tres aparatos del organismo:

- Aparato respiratorio, el cual está formado por la nariz, la boca, la laringe, la tráquea, los bronquios y los pulmones. Su función consiste en almacenar el aire y hacer que circule de afuera hacia adentro y viceversa.

- Aparato fonador, que comprende la laringe y las cuerdas vocales. Su función es producir el sonido.

- Aparato resonador, formado por la laringe, los dientes, el paladar, la lengua, las mejillas y los labios. Su función es amplificar y dar sonoridad.

El funcionamiento de estos tres aparatos, en la producción de la voz, se da gracias al proceso de la respiración; sin éste la producción del sonido no sería posible (Vega, 2004).

En el siguiente dibujo se pueden observar los elementos que forman los aparatos fonador y resonador.

Figura 1. Corte esquématico del aparato fonatorio humano.

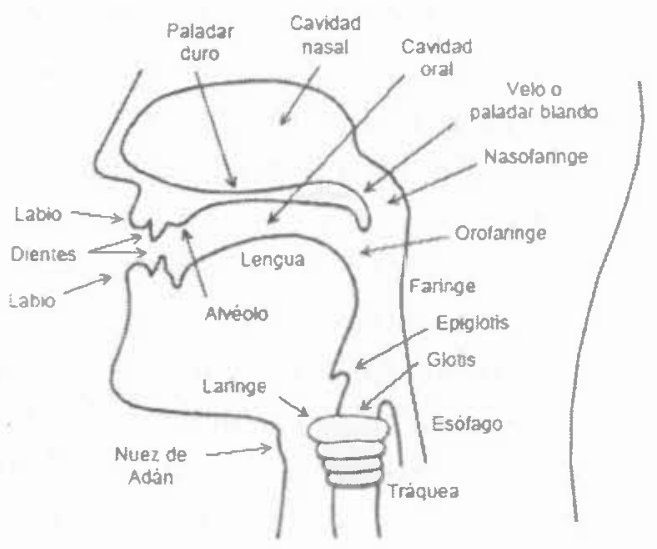




\section{Aspectos por tomar en cuenta para una buena voz}

La voz es el instrumento fundamental de comunicación que utilizan las personas; en el caso de muchos profesionales, entre ellos los maestros, como ya se dijo; es también su herramienta de trabajo. En el grupo de los docentes existe un alto porcentaje que usa mal la voz, por lo que es imprescindible que se dé un cambio en los hábitos comunicativos.

Es necesario aprender a utilizar correctamente la voz, para esto se necesita tener conocimiento sobre el mecanismo de la fonación y los recursos de la voz, tomar conciencia de los propios hábitos, para corregirlos mediante el ejercicio y la automatización de los mecanismos más adecuados (Tejeda, s. f.).

De acuerdo con Ruiz (s. f.), es necesario manejar, de manera apropiada, varios aspectos para que la voz suene intensa, calmada, agradable y educada; éstos son: la respiración, la dicción, el volumen o intensidad, el tono, la velocidad, la pronunciación, el énfasis, el timbre y las pausas.

Respiración

El respirar bien es importante para articular la voz, pues esto ayudará al comunicador no sólo a disminuir o eliminar el nivel de tensión nerviosa que se manifieste en él, sino que también le permitirá manejar su voz, convenientemente, en cuanto a intensidad, a expresión y a entonación; le facilitará graduar los ritmos y las pausas, aspectos importantes en la comunicación oral.

En una buena respiración, el aire entra por las fosas nasales, llega hasta los fuelles pulmonares, se dirige hacia el diafragma, este músculo impulsa el aire hacia la laringe; el aire allí se convierte en sonido por la vibración de la mucosa 
de las cuerdas vocales. El sonido producido en la laringe, al principio, será débil, con muy poco volumen, con ausencia de calidez, muy simple.

Ese sonido se coloca en un lugar de resonancia, cuyos elementos más importantes son: el seno frontal, ubicado en la frente; los senos maxilares, ubicados en los costados de la nariz y debajo de los ojos y los senos etnoidales, ubicados en la pirámide de la nariz. Es en estos resonadores en donde, según sea colocado el sonido, se transformará su timbre, enriqueciéndolo con volumen, intensidad, belleza, armonía (Loza, s. f.).

\section{Dicción}

Alayón (s. f.) dice que la dicción es la manera como una persona pronuncia cada fonema (sonido) que forma una palabra. Costa Rica y cada una de sus regiones, tiene sus particularidades en cuanto a pronunciación; sin embargo, hay ciertos aspectos que se deben tomar en cuenta a la hora de hablar.

Hay que cuidarse de pronunciar, correctamente, las eses finales de las palabras, como por ejemplo en la palabra Puntarenas; pronunciar la ese del grupo "ns", como en la palabra construcción; pronunciar la "d" final como "d" y no como " $\mathrm{t}$ " (ciudad); no suprimir letras de los grupos "ado", "ido", como en mercado y molido; pronunciar la " $x$ " con el sonido fuerte (ks), así externo se pronunciaría "eksterno" y no con sonido suave (esterno). Por último, se debe tener mucho cuidado con la pronunciación de " $r$ " final y del grupo "tr" en cualquier posición de la palabra, pues por la emisión de este sonido es que se reconoce a los ticos en cualquier parte del mundo. 


\section{Volumen o intensidad}

Es el nivel sonoro con el que se proyecta la voz, es la propiedad que depende de la mayor o menor amplitud de las ondas sonoras (Posada y Zuliani, s. f.).

Ahora existen equipos para amplificar la voz, sin necesidad de forzarla, pero si no los hubiera se puede determinar si se está hablando con un volumen conveniente por las expresiones de los escuchas de las primeras y de las últimas filas. Si hay duda, se puede preguntar si le escuchan o no.

\section{Velocidad}

En todos los países de habla hispana se utiliza una velocidad diferente para hablar, así, por ejemplo, los venezolanos lo hacen velozmente, mientras que los nicaragüenses lo hacen en forma pausada.

Si se preguntara: ¿Cuál es la velocidad que se debe usar cuando se habla?, habría que contestar: "Aquella con la cual el interlocutor capte y entienda lo que se le está hablando".

Si alguien habla muy rápido, corre el riesgo de fatigar a los escuchas, además de que se dificulta la dicción; si, por el contrario, habla muy lentamente, terminará por aburrir y desesperar al sujeto receptor.

La lentitud o la rapidez al hablar puede depender del tema que se está tratando y del auditorio al que se le esté hablando. Por un lado, si se habla de un tema desconocido o difícil, se tendrá que hablar más lentamente que cuando sea conocido o de fácil asimilación; por otro, si se dirige a personas de bajo nivel cultural o muy jóvenes (niños o adolescentes), la rapidez será menor que cuando el discurso sea para personas de un nivel más elevado o de mayor edad (ITCR, 1979). 
Según la Real Academia Española (2001), tono es la inflexión de la voz y modo particular de decir una cosa, según la intención o el estado de ánimo de quien habla. Generalmente, las personas al hablar utilizan los diferentes tonos sin pensarlo, sin darse cuenta y sin tener que practicar.

Así, una entonación ascendente indica interrogación, indecisión, incertidumbre, duda o suspenso; una modulación descendente sugiere firmeza, determinación, certeza, decisión o confianza. Una inflexión doble puede sugerir una condición de conflicto o una contradicción de los significados y se usa, a menudo, para denotar ironía o sarcasmo o para exponer una sugerencia.

Estas variaciones de tono utilizadas en la comunicación, se usan, fundamentalmente, para transmitir las ideas con más claridad; por eso es importante que los docentes puedan manejarlo apropiadamente en el aula.

\section{Pronunciación}

Consiste en la correcta articulación, modulación y duración del sonido (ITCR, 1979). Para lograr una mayor inteligibilidad de los sonidos vocálicos debe ser más larga.

Para que los oyentes entiendan justa y exactamente lo que se expone, es necesario que se pronuncien y se modulen todas las palabras con claridad, sin exagerar con muecas a la hora de hablar, sin alterar demasiado la velocidad y sin subir el volumen innecesariamente.

Énfasis

Corresponde al subrayado de la comunicación escrita y se produce haciendo un mayor esfuerzo de voz en la(s) 
sílaba(s) o palabra(s) que se desea(n) resaltar. Se utiliza para que el escucha se dé cuenta de cuáles son las palabras o las ideas más importantes, presentadas por el sujeto-emisor.

El uso impropio del énfasis podría servir de motivo para que los escuchas pierdan interés en la exposición oral. Si no se enfatiza nada, el sujeto-receptor se aburriría por lo monótono de la disertación y porque no podría determinarse qué es más o menos trascendente. $\mathrm{Si}$, por el contrario, todo se enfatiza, el escucha se cansaría y no sabría distinguir la significación de las ideas, pues todo parecería importante.

\section{Timbre}

La Real Academia Española (2001) dice que es la calidad de los sonidos, que diferencia a los del mismo tono y depende de la forma y de la naturaleza de los elementos que entran en vibración. El timbre es el componente básico de una buena voz, pues es la calidad que la hace agradable, es la característica individual o modo propio de sonar la voz, es decir, es lo que permite diferenciar una voz de otra.

En cada persona existe un timbre óptimo, el cual depende del tamaño, de la forma y del cuidado para conservar las cuerdas vocales. Ese timbre se consigue cuando se logra una relación equilibrada entre las resonancias bucal y nasal, ya que se evita la tensión excesiva de las cuerdas vocales y el jadeo que, a veces, se oye al hablar, producido por una incorrecta respiración.

Una voz es agradable y melodiosa si no es débil, ronca, chillona o nasal. Si se tiene la voz débil, se debe tratar de hablar usando un tono más bajo y, al mismo tiempo, se da más intensidad a la emisión sonora. Se debe abrir más la boca, especialmente en los sonidos vocálicos, con el fin de 
aumentar el volumen de la cavidad bucal y mejorar el efecto de resonancia (ITCR, 1979). Estos cuidados se deben tener, también, en el caso de poseer una voz chillona.

Si se tuviera una voz ronca, se debe hacer lo contrario a lo anotado para la voz débil, esto es: tratar de cerrar un poco la boca para disminuir el volumen de la cavidad bucal y, así, aminorar la resonancia de la voz.

La voz nasal se 'combate' si se vence el nerviosismo, si se habla un poco más pausado, si se adopta una posición y una actitud relajadas y si se vocaliza lo mejor posible, abriendo bien la boca, sin exagerar hasta verse ridículo (ITCR, 1979).

\section{Pausas}

La utilización de las pausas (intervalos de silencio) es tan importante como el hablar, pues produce diversos efectos en el sujeto-escucha, según el tipo.

Las pausas pueden ser: psicológicas, lógicas, afectivas o respiratorias. Las psicológicas se dan cuando la persona que está hablando hace un silencio corto, con la intención de que el escucha reflexione un poco acerca de lo que se dice o, también, para que reflexione sobre algo que se considera importante. Las lógicas son aquellas propias del texto, corresponden a los signos de puntuación de la comunicación escrita. Las afectivas son las que se llevan a cabo para mover a la emoción del oyente, y las respiratorias son las que se realizan cuando al sujeto transmisor se le agota el aire y siente la necesidad de respirar.

Todos los tipos de pausa se usan naturalmente, no hay que planearlas ni forzar su utilización. Un buen manejo de las pausas enriquece el discurso, lo hace más agradable, más efectivo y con un tono más variado (ITCR; 1979).

Hay que tomar en cuenta que no hay muestra más segura del carácter de una persona como la voz. Una 'buena' voz 
proyecta una imagen favorable que ayuda a que las ideas del sujeto expositor parezcan más interesantes y significativas; una voz 'pobre', todo lo contrario.

Para que la comunicación resulte más eficaz, se puede mejorar la voz mediante la práctica, siempre y cuando se realice en forma sistemática y que se conozcan las cualidades de una buena voz, los mecanismos que la producen y los métodos para lograr dichas cualidades.

\section{Impostación de la voz}

\section{Definición}

El vocablo impostación viene del latín "imposta" que significa "poner sobre". Impostar la voz consiste en colocar, apropiadamente, los órganos de la voz, con el fin de que el sonido se proyecte de manera agradable, sin dudar ni temblar, hasta la última fila del auditorio. El sonido producido en la laringe se coloca en las cavidades de resonancia, a fin de que con un mínimo de esfuerzo se obtenga el máximo rendimiento fonatorio.

La impostación consiste, entonces, en disponer la voz, de tal manera, que resulte sonora, bella, fácil. Dicho de otra manera, el aliento exprimido y contenido por el diafragma, en forma educada, hará vibrar la laringe (y las cuerdas vocales), lo que permitirá que estas vibraciones, después de una libre sonoridad en los resonadores, salga por la boca transformado en voz impostada. Se trata, pues, de sacar el máximo provecho de la caja de resonancia, esto es, que la voz resuene dentro de la cara.

Importancia y características

Según Loza (s. f.), la impostación de la voz es importante por varias razones: 
- Por la fácil emisión de la voz, para lo cual se debe usar una buena cantidad de aire.

- Por la descompresión de los músculos de los costados del cuello.

- Por la existencia de tonos, sobre todo, agudos, con lo que la voz gozará de un timbre agradable.

Alayón (s. f.) considera que la voz impostada presenta tres características fundamentales: apoyo, colocación y proyección.

- El apoyo se logra mediante una respiración diafragmática y luego contrayendo, levemente, los músculos abdominales. Esta contracción será mayor o menor, de acuerdo con el mayor o menor volumen que necesite la emisión de voz; una operación muy similar a la que se realiza cuando se ríe a carcajadas, de hecho éste es el ejercicio que se recomienda para desarrollar el apoyo: reírse a carcajadas fingidas ( $\mathrm{ja}, \mathrm{ja}, \mathrm{ja}$ ). El apoyo da consistencia sólida a la columna de aire y prepara una buena colocación.

- La colocación es el alzamiento del velo posterior del paladar, esa zona conocida, popularmente, como "campanilla", en la parte posterior de la boca. Cuando este paladar se alza, la voz se orienta hacia los senos paranasales, unos resonadores naturales que hay en el rostro, y el efecto es como el de un cajón de resonancia de una guitarra: la voz se amplifica con economía de esfuerzo, pues cuando la voz está bien colocada el sonido aumenta, en tanto que la emisión de aire es menor. La operación parecida a este alzamiento del paladar es la que se efectúa al bostezar: El ejercicio recomendado es hacer respiración abdominal, dar apoyo y emitir la sílaba "mi", tratando de mantener alzado el paladar posterior como cuando se bosteza. 
- La proyección es, simplemente, tener conciencia del alcance de la voz, de su profundidad de campo, de modo que no se peque de exceso ni de defecto de volumen en la proyección, atormentando a los más próximos o dejando sin poder escuchar a los más distantes.

Como sucede con cualquier disciplina, los ejercicios siempre ayudan a mejorar las habilidades, si se practican ejercicios para la voz, aunque sea sólo para mejorarla un poco, se puede sacar más provecho en los discursos y presentaciones porque sonará vigorosa, equilibrada, agradable al oído y culta (Ruiz, s. f.).

Enfermedades más comunes de la voz

Muchísimos docentes padecen problemas de la voz, a causa de, principalmente, malos hábitos, los que, por suerte, son fáciles de corregir.

Las causas más comunes que producen trastornos de la voz son, en primer lugar, los resfríos y, en segundo lugar, los malos hábitos en su uso. Las alteraciones vocales se manifiestan en un decaimiento de la calidad y eso puede ocurrir por causas anatómicas, fisiológicas o psíquicas, las que afectan el aparato productor.

Los trastornos de la voz más significativos son las disfonías y las afonías.

\section{Disfonías}

Consisten en un desorden de la voz, bien laríngeo o respiratorio, que afecta el volumen, el timbre y la modulación vocal. Las disfonías pueden ser de dos tipos: 
- Funcionales, provocadas por un inadecuado control de la voz por causas diversas.

- Orgánicas, provocadas por una malformación o defecto en alguno de los elementos del aparato vocal.

Estos trastornos pueden ser temporales o permanentes.

Afonía

Es la alteración máxima de la disfonía y en todas las características de la voz, es decir, su pérdida total (Alteraciones de la voz, s. f.).

Son muchos los docentes que se incapacitan por dificultades con su voz, por eso hay que prevenir los problemas con este aparato tan importante para su profesión; y si acaso llegan, saber cómo combatirlos para continuar con las labores en el aula.

Prevención de los problemas de la voz

Un docente, por obligación debe hablar por muchísimas horas durante el día, por tanto, es necesario aprender a prevenir las alteraciones de la voz, $\tan$ frecuentes entre los profesionales de la enseñanza

Es sabido que en Costa Rica la mayoría de las instituciones educativas carece de las mejores condiciones, en los distintos campos, para evitar los problemas; por ejemplo, la infraestructura no posee el aislamiento acústico recomendable; el número de alumnos por grupo es muy alto, las aulas no tienen las mejores condiciones de limpieza, por lo que el polvo y la tiza llegan a menudo a la garganta del docente.

Hay que insistir que, además de estos aspectos, existe otra razón para que la garganta de los docentes sufra dolencias 
a menudo, ésta es el mal uso y el abuso de la voz. Por tanto, es muy importante que se adquieran hábitos correctos y que se sigan unas normas básicas de higiene, para prevenir ese abuso y mal uso de la voz.

Según Educar (2001), el evitar el abuso de la voz implica, entre otros hábitos, no elevar el volumen para dejarse oír por encima de los ruidos ambientales (música, carros, otras voces), no sólo en clase, sino también en otros ambientes.

Tampoco recomienda forzar la voz cuando se realiza un ejercicio físico, ni sentarse o permanecer de pie de manera incómoda: es necesario mantener una postura corporal correcta, sea de pie o en una silla. Además, aclara que el mal uso de la voz está motivado por la creencia generalizada de que se habla con las cuerdas vocales, cuando, en realidad, éstas sólo emiten unas órdenes sonoras en las que influyen la respiración, la vocalización y _.. impostación dada a la voz.

Recomendaciones para el cuidado de la voz

Morrison (citado en Síntomas de un desorden de la voz, s. f.) propone algunas de las siguientes recomendaciones para el cuidado y uso óptimo de la voz; éstas se pueden adaptar a las necesidades de los docentes. De su uso habitual, se llega a la implantación de hábitos saludables en el uso y la conservación de la voz.

- Establezca el origen de la tos y el carraspeo (si los tiene) para poderlos controlar efectivamente.

- Controle la intensidad de su voz en todas sus presentaciones.

- Cuando hable en ambientes ruidosos, utilice amplificación.

- Si utiliza la voz cantada conozca la clasificación de su voz, y cante sólo dentro de su gama vocal. 
- Controle la energía de proyección vocal para hablar en público.

- Disminuya el uso de la voz cuando en forma simultánea deba realizar un ejercicio físico fuerte.

- Entrene su voz para usarla con un tono apropiado y con inflexiones adecuadas.

- Entrene la respiración para usarla en forma coordinada con la fonación.

- Manténgase relajado al hablar: cuerpo, mandíbula, lengua. No utilice la voz cuando la sienta tensa o cansada.

- Utilice la voz con moderación.

- Cuando detecte síntomas de desorden de la voz, consúltelos para que sean estudiados y controlados, en forma oportuna.

- Reconozca los signos de alerta, esto ayudará a prevenir la aparición de un desorden de la voz.

- Realice un trabajo de control postural para usar su voz eficientemente.

Otros consejos útiles para cuidar la voz, ofrecidos por Naidich (2004) son los siguientes:

- Hablar mucho o en voz alta puede llevar a un desorden de la voz. Es conveniente considerar el entrenamiento vocal cuando hay que hablar o cantar en voz alta, o cuando hay que usar la voz para trabajar.

- Algunos medicamentos, como por ejemplo, los que se toman para combatir los resfríos o las alergias, producen deshidratación de las cuerdas vocales y mejoran los síntomas, pero 'secan' los tejidos del tracto vocal y respiratorio.

- Es conveniente consultar con el médico antes de automedicarse. Si se necesita tomar medicinas debe ingerir, además, mucha agua y tratar de mantener el ambiente del trabajo y el hogar con una humedad del $40 \%$. 
- La tensión podría llevar a una forzada producción de la voz y esto puede provocar daños en el tracto vocal. Las técnicas de relajación ayudan a mejorar la voz, y permiten lograr hablar por largos períodos con efectividad.

- La disfonía o alguna alteración al respirar o al tragar, pueden ser señales de desórdenes en el tracto vocal. Si algunos de estos síntomas persisten por más de 15 días, se debe consultar al laringólogo.

- La cafeína y el alcohol provocan deshidratación de las cuerdas vocales. El consumo moderado de estas sustancias y el beber mucha agua ayudarán a combatir este efecto. Por cada taza de café que se tome es aconsejable beber un vaso de agua.

- 'Aclarar la garganta' y toser frecuentemente, puede dañar los tejidos de las cuerdas voca.es. Es conveniente tomar sorbitos de agua, y chupar un caramelo para aliviar o calmar esa molestia.

- El fumar es la causa principal del cáncer de laringe y, además, provoca distintos tipos de enfermedades en las cuerdas vocales (laringitis crónica, edema de Reinke y otras).

- La frecuente sensación de quemadura detrás del esternón, la acidez o el sabor agrio en la boca, está indicando que los ácidos del estómago están pasando por el esófago y se vierten dentro de la laringe, lo cual es anormal. Hay que evitar las comide.s zopiosas, con grasas, fritas, el café, el alcohol y evitar también, acostarse inmediatamente después de comer.

El primer paso para usar la voz efectivamente y mantenerla sana, es la motivación para convertir los cuidados de la voz y la realización de los ejercicios en una rutina diaria y en una forma de vida. 


\section{Conclusiones}

Cada rama profesional cuenta con objetos, con materiales, con instrumentos, con ayudas para que su labor se lleve a cabo de una manera eficiente y conforme con lo que se espera en ella. En el campo educativo, los docentes tienen un instrumento invaluable, natural y fácil de manejar: su voz, la cual es subutilizada, muchas veces, o utilizada al extremo, pero mal, esto por ignorancia (en el buen sentido de la palabra).

La mayoría de los docentes no explota positivamente su voz, pues la utiliza de manera equivocada y abusa de sus bondades; creen que porque es un bien natural no merece ser cuidada, y esa es una de las principales razones por las que se extienden tantas incapacidades a los miembros de ese grupo profesional.

Sería tan sencillo que las personas, así como cuidan y dan mantenimiento a sus casas y a sus vehículos, lo hicieran también con su cuerpo y, especialmente, con su voz; pero no, a esos aspectos no le dan importancia, creen que se cuidan y se mantienen 'naturalmente', y todo por ser bienes obtenidos de forma gratuita.

Los foniatras y los logoterapeutas son los profesionales encargados de aconsejar acerca de los cuidados de la voz y de su buen uso y mantenimiento; pero si se tuviera conciencia del valor de la voz y de la importancia de mantenerla en buenas condiciones, no habría necesidad de llegar a una crisis en ese campo, ni tener que visitar a alguno de esos profesionales de la voz.

Cada docente podría convertirse en un doctor para sí mismo, si usara apropiadamente la voz, si no abusara de ella y si siguiera las normas lógicas requeridas para mantenerla de manera óptima. Es necesario que cada uno de los profesionales educativos se dé cuenta de la importancia de tener 
en buen estado la mejor y más barata herramienta de trabajo: su voz.

Para cada uno de los aspectos de la producción de la voz que se manejaron en este trabajo, existe una serie de ejercicios correctivos (véase el anexo), fáciles de realizar a cualquier hora y en cualquier lugar. Ninguno necesita un equipo especial ni un esfuerzo sobrehumano para llevarlos a cabo, lo único que se requiere es un poco de voluntad, para ejecutarlos habitualmente; cuando esto se logre, se podrá ver lo positivo de ellos en la voz.

Con lo anterior, el desempeño laboral será más placentero para todos los sujetos involucrados con el ámbito educativo; el éxito en su campo será reconocido rápidamente, lo que hará que se sientan aún mejor.

Si todo ser humano tiene que manejar su voz, muy a menudo, para comunicarse con sus seme, antes de una manera efectiva y, aún más, si esa voz ayuda en su desempeño profesional, es necesario que esté en las mejores condiciones.

Usted, educador(a) o futuro(a) educador(a), ien qué condiciones se encuentra su voz?, ¿está conforme con la manera en que la usa?, ¿siente algún malestar en la garganta después de una sesión de trabajo?, ¿considera que esa 'herramienta' le va a durar buena todos los años que le faltan de trabajar?, ise queja alguno de que no le entiende cuando usted habla o que su voz es cansada o ahurrida?..., revise las respuestas a estas preguntas y analice si crı e ver una señal de que necesita hacer un alto en el camino, hacerse una revisión, brindar un poco de cuidado a la voz y buscar la solución a su problema; no lo deje para después. ¡Mañana puede ser demasiado tarde! 